\title{
ENTRE O HISTÓRICO E O LITERÁRIO: UM ESPAÇO DE CONFLUÊNCIAS
}

Dinameire Oliveira Carneiro Rios ${ }^{84}$

RESUMO: Neste trabalho são analisadas as relações estabelecidas entre a literatura e a história dos últimos séculos. Parte-se da acepção construída por Aristóteles acerca da diferenciação entre o poeta e o historiador, que serviu durante muito tempo para nortear as discussões sobre o diálogo entre os dois campos, para construir considerações acerca dessa relação, principalmente a partir do século XIX, quando a história buscou consolidar-se enquanto ciência e se afastar de conceitos comuns ao âmbito da literatura, como a fabulação e a imaginação. As reflexões são estendidas até o século XX em que se considera como aspecto importante do contato entre os campos a abertura empreendida pela história em relação a outras áreas do saber.

Palavras-chave: Literatura. História. Diálogo.

ABSTRACT: This work analyzed the relations between literature and the history of the last centuries. Part is the meaning built by Aristóteles about the difference between the poet and the historian who has long served to guide the discussions on the dialogue between the two camps, to build considerations about the relationship, particularly from the nineteenth century, when the story sought to consolidate itself as a science and away from common concepts to the realm of literature, such as confabulation and imagination. The reflections are extended until the twentieth century that is considered as an important aspect of contact between the fields opening undertaken by history in relation to other areas of knowledge.

Keywords: Literature. History. Dialogue.

Os empréstimos feitos entre a literatura e a história vêm de longa data, porém ainda hoje essa relação se encontra num campo dialético marcado pelo acirramento. Os diálogos frutiferos entre a literatura e $\mathrm{O}$ registro factual renderam obras de grande importância como A Iliada, de Homero (século IX ou VIII a.C.), e Guerra e Paz, de Tolstói (1828-1910), porém a complexidade que envolve essa relação se atenua quando o

${ }^{84}$ Doutoranda em Literatura e Cultura na Universidade Federal da Bahia - UFBA. 
inverso, o que a história abstrai do campo literário, entra em questão. Isso se dá principalmente pelo caráter científico perquirido pela história durante o século XIX, o que para alguns historiadores seria ameaçado pela proximidade do discurso histórico com a arte, que nada ou muito pouco teria de ciência.

Embora a preocupação com as fontes do que era considerado histórico não tenha ocupado grande espaço entre os historiadores da Antiguidade, é imprescindivel notar que a relação entre literatura e história já fazia parte das reflexões de Aristóteles (384 - 322 a.C.) ao analisar os aspectos da construção poética. $O$ filósofo grego, ao lançar as bases da literatura ocidental, através da sua Poética, concebeu o conceito de mimesis pelo seu valor autônomo e estético, desvinculando o discurso literário do imbróglio de mera imitação do mundo exterior. Segundo ele, a mimesis confere à arte a possibilidade de sustentação puramente pelo critério de verossimilhança, podendo pertencer ao plano da ficção sem o invólucro de dependência em traduzir o que seria o plano empírico, real. Isso pode ser pensado, à primeira vista, como uma notável distinção da literatura e da história diante do real, pois, enquanto a primeira pode se construir puramente através de sua interioridade, a segunda está fortemente direcionada ao externo, ao mundo factual. O filósofo defendia ainda que o que vai diferenciar, por exemplo, o discurso do poeta e do historiador não é propriamente a forma com que cada um escreve, sendo o primeiro verso e o segundo prosa, mas os tipos de fatos sobre o qual cada um escreve, uma vez que o historiador discorre sobre fatos que aconteceram, enquanto o poeta sobre aqueles que poderia ter acontecido, tornando o seu discurso mais universal. Assim, caberia à literatura a função de criar, imaginar e apresentar os fatos de modo original, mas não construindo uma narrativa que trate dos fatos exatamente como ocorreram.

A distinção de Aristóteles serviu durante muito tempo para nortear as discussões sobre o diálogo entre os dois campos, porém o modo como a história se relacionou com o uso de elementos pertencentes à literatura, como a fabulação e a imaginação, sofreu inúmeras transformações a partir de meados do século XVIII.

Ao construir um panorama sobre a relação entre história e ficção, White (2001) afirma que mesmo antes da Revolução Francesa alguns historiadores reconheciam o caráter "imaginativo" que a história possuía, chegando a ser considerada como um "ramo da retórica". Já durante o século XVIII, segundo afirma White (1994) a historiografia era divida em basicamente três tipos: fabulosa, verdadeira e satírica. Ao primeiro tipo 
ficavam restritas as construções em que os fatos eram organizados de modo a parecer verossímeis, por serem eles produtos da imaginação, e que tinham como objetivo a mera diversão, recreação do público leitor, que geralmente era composto por pessoas menos letradas ou sérias. Esse tipo de fazer histórico era o oposto do que defendia historiadores como Pierre Bayle, para quem a verdade deveria ser sempre o foco "na medida do humanamente possivel" (WHITE, 1994, p. 63). Porém posicionamentos como estes, que anos mais tarde foram encontrados em historiadores como Voltaire, escondiam a manipulação de pretensas "verdades" que pareciam melhor agradar a determinados posicionamentos, enquanto o oposto soava como falsificação. Enquanto isso a história verdadeira, no extremo à fabulosa, assentava-se na verdade dos fatos, pois ainda que eles pudessem suscitar interpretações diversas, eles próprios, distanciados de verdades de cunho moral, estético e intelectuais, eram capazes que carregar em si o que é propriamente "verídico". Diante de três modos distintos de escrever a história, somente um quarto tipo, colocado em um patamar de superioridade frente aos outros, seria capaz de analisar a validade do que era produzido, relativizando a aparente completa oposição entre o que seria factual e o que se designava como fantasia, coisa que para os iluministas deveria ser medido por meio da razão.

Na concepção da escrita histórica criada pelos iluministas, a verdade poderia ser separada do fabuloso através do filtro racional. Ora, sendo assim, tudo o que fosse fruto do imaginativo seria facilmente descartado na construção da escrita histórica, pois a razão possibilitaria julgar os construtos produzidos por meio da fabulação e aqueles oriundos da experiência sensorial racional. Nesse caso ficava de lado tudo o que fosse proveniente das narrativas de caráter mítico, lendário ou fabuloso, o que era considerado "verdade", de fato, se tratava de uma parcialidade do passado recortado pelo crivo da racionalidade, excetuando todo um aspecto do passado que chegava até o presente somente por meio de tais narrativas "imaginativas".

O único lugar em que o fabuloso teria pleno espaço seria no campo da arte, pois vedada a sua entrada no processo de criação dos relatos históricos, somente dentro da expressão artística o elemento fantasioso poderia imprimir sua autoridade, visto que a arte se contrapunha à "vida", preocupação central dos historiadores. Essa contraposição, além de romper com a ideia de que a arte também se centra sobre (e primordialmente) a vida, destituía qualquer possibilidade de os objetos de cunho artístico também serem capazes de recuperar os fatos do passado e reconstituí-lo. 
Assim, para os iluministas, enquanto a "vida" seria regida pela razão, que guiava as produções históricas, a arte se orientava a partir da "desrazão", ainda que tivesse que se nortear sobre o que era puramente fantasia e o que era "verdade".

Porém, embora existisse essa rigidez entre alguns historiadores da época, era quase consenso aceitar que na sua escrita, a história exigia o uso de processos análogos ao da escrita literária, porém, em sua recepção, o texto deveria ser lido a partir da junção de princípios tantos da literatura quanto da ciência. O que estava em jogo nesse caso não era a oposição entre o que seria verídico e o que seria fantasioso, mas o julgamento do que poderia ou não ser tido como "verdade", visto que as técnicas de escrita estavam muito próximas da narração considerada fantasiosa, imaginativa. Era comum o uso de "artifícios retóricos, tropos, figuras e esquemas de palavras e pensamentos, os quais, na forma como eram descritos pelos retóricos clássicos e renascentistas, eram idênticos às técnicas da poesia em geral" (WHITE, 2001, p. 139).

O que se pode depreender desse contexto é que, ainda que a história usasse como empréstimo o modo de narrar da literatura para dar validade aos fatos considerados de importância histórica, a própria literatura seria incapaz de revelar através do seu discurso a verdade encoberta pelos escombros do passado. É sobre a linha tênue que atravessa a construção dos dois discursos que Barthes chega a questionar:

[...] a narração dos acontecimentos passados, submetida comumente [...] à sanção da "ciência" histórica, colocado sob a "caução" imperiosa do real, justificada por princípios de exposição "racional", [...] difere realmente, por algum traço específico, por uma pertinência indubitável da narração imaginária, tal como se pode encontrar na epopéia, no romance, no drama? (BARTHES, 2004, p. 163-164)

Para os historiadores do século XVIII, o alcance da "verdade" pela história se dava não somente pela apropriação de uma técnica na composição do enredo ou nos domínio dos fatos que compõem tal relato, mas através da associação entre o modo de abordagem específico e a apropriação do fato, o que condiziria à "verdade", sem que a imaginação fosse descartada desse processo. Porém, é durante o século XIX que os posicionamentos mais radicais quanto à relação entre a "verdade" e o ficcional começam a aflorar. Nesse contexto, os historiadores passam a 
acreditar que a "verdade" estaria nos próprios fatos, sem que fosse preciso o uso de técnicas na composição narrativa ou mesmo de uma abodagem que necessitasse traz à tona o que estava escondido por trás dos eventos. $\mathrm{O}$ discurso histórico seria capaz de reconstruir os fatos a partir de uma exatidão científica, o que distanciaria o objetivo do fazer histórico do fazer literário, pois enquanto esse se preocupava somente como o imaginável ou passivel de acontecer, aquele se debruçava sobre a realidade conforme ela se apresentava na ordem dos fatos, alijando diametralmente os dois campos e se aproximando, em certo sentido, da definição proposta por Aristóteles.

Como confirma White (1994), esse posicionamento categórico germinou em um contexto pós-Revolução em que os fracassos, as exasperações, as interpretações errôneas e as decisões radicais foram produzidos a partir da análises dos fatos que em muito se baseavam em um pensamento mítico acerca do passado e que, por isso, havia, a partir de então, a fremente necessidade de construir um discurso histórico que se situasse além das possibilidades de interpretações duvidosas e que superasse a dicotomia política instaurada na época. É nesse contexto que a história, já considerada uma disciplina erudita, tenta se desenhar como objetiva, científica e que situava seu discurso dentro de um patamar de realismo que não abria espaços para interpretações dúbias. Os historiadores defensores desse status da história tentaram dissassociar a toda custo qualquer vinculação entre o que era histórico e o que era ficcional/mítico, distanciamento desejado ainda mais em momento em que a literatura de caráter romântico tinha sua base apoiada em narrativas fortemente fantasiosas.

Além de desconsiderar as distinções entre mito e ficção, muitos historiadores da do século XIX levaram à risca a oposição entre o "real" e o "ficcional" na tentativa de desvincular a história da perspectiva subjetiva, porém, como argumenta White (1994), muitos historiadores da época

[...] não compreendiam que, quando se trata de lidar com fatos passados, a consideração básica para aquele que tenta representá-los fielmente são as noções que ele leva às suas representações das maneiras pelas quais as partes se relacionam com o todo que elas abrangem. Não compreendiam que os fatos não falam por si mesmos, mas que o historiador fala por eles, fala em nome deles, e molda os fragmentos do passado num todo cuja integridada é - na sua representação - puramente discursiva. Os romancistas 
podiam lidar apenas com eventos imaginários enquanto os historiadores se ocupavam dos reais, mas o processo de fundir os eventos, fossem imaginários ou reais, numa totalidade compreensivel capaz de servir de objeto de uma representação é um processo poético. (WHITE, 1994, p. 141, grifos do autor).

Logo, se havia alguma distinção possivel entre os dois, ela estaria relacionada ao caráter do conteúdo abordado, pois em ambos os discursos a construção da "verdade" que seria aceita como tal pelo leitor a partir do seu aspecto "bem acabado" e verossímil desaguaria novamente na capacidade de organização, filtragem, escolhas e manipulação do escritor acerca dos elementos oferecidos pela linguagem, impossibilitando a extração dentro desse processo da atuação do historiador enquanto autor. Assim, do mesmo modo que o escritor precisa organizar as ideias que são oferecidas pela imaginação para a composição de um mundo ficcional lógico e coerente, de maneira análoga o historiador deve agrupar os fragmentos que o passado oferece para ordenar os fatos, e, para ambos, o que possibilita isso é o trabalho com a linguagem. Para White (1994, p. 140), a constatação de que a história, mesmo no século XIX, continuou adotando as técnicas da literatura, pois era "impossivel escrever história sem recorrer às técnicas do orador e do poeta”, foi que para cada movimento da literatura ocorrido durante esse século é possível encontrar um historiador "científico" que adotou um discurso equivalente. Assim foi possivel encontrar autores da corrente romântica, como Michelet, realista, como Ranke, simbolista, em Burckhardt, enfim, "houve tantos 'estilos' de representação histórica quantos estilos literários identificáveis no século XIX" (WHITE, 1994, p. 141).

A constatação de existência de tantas formas distintas de escrever história no século XIX desconstrói a ilusão alimentada por muitos historiadores da época de que era possivel produzi-la sem qualquer intervenção subjetiva de quem a escreve. Os fatos dispersos do passado, que são articulados através da linguagem, só passam a fazer parte da história depois de organizados e ordenados, a partir da percepção do historiador, impossibilitando que se pense numa autonomia por parte dele e, consequentemente, numa desvinculação da atuação subjetiva do historiador na construção do discurso.

O que é notável ainda dentro desse contexto é que enquanto a objetivo da história era despir-se daquilo que ameaçava o seu caráter 
cientifico, a literatura, num caminho simultâneo, tentava livrar-se de seu lado retórico e empreendia a construção de um discurso que se aproximava do histórico. Isso se manifestou com maior força no romance histórico romântico e a partir do surgimento do realismo e no naturalismo, numa oposição à estética romântica que se apoiava, de modo amplo, no imaginário e na fantasia para a construção literária. Porém, mesmo diante disso, é possível imaginar o porquê de a história tentar desvincular-se do ficcional, afinal, ainda que se baseasse em elementos da exterioridade, o papel do historiador não podia ser confundido com o do narrador de um romance por esse, em sua onisciência, revelar o que não era domínio da história, dita objetiva.

Em alguns dos estudos teóricos realizados por Henry Fielding ainda no século XVIII é possível constatar a preocupação do autor inglês em relação aos limites que envolviam os discursos da literatura e da história. Inclinado a pensar a literatura a partir da perspectiva da mimese aristotélica, que o ajudou a organizar suas narrativas em torno da organicidade dos enredos, Fielding também era afeito às narrativas épicas, porém, como destacou na introdução do seu romance Tom Jones (1749), o escritor deveria dosar o uso do fantasioso e aplainar a narrativa na verossimilhança, afinal, o contexto das narrativas homéricas possibilitava a exploração do mítico e do fabuloso, situação diferente do autor oitocentista. Foi pensando o quanto o escritor de romance deveria empenhar-se na construção de narrativas verossímeis e centradas em ocorrências que fossem prováveis de acontecer no plano do real que Fielding se aproximou das relações entre história e literatura. Estavam em voga na época as discussões sobre a interação entre história e romance, pois, além de o segundo buscar se legitimar diante da epopeia, por exemplo, era preciso identificar o romance como uma possibilidade de registrar a vida como ela era. Por isso Fielding, assim como vários outros escritores de sua época, aproximou o romance da história com o objetivo de mostrar a superioridade do primeiro, pois, como chegou a afirmar "o romancista pode até cometer erros quanto aos detalhes factuais, mas pinta as pessoas como verdadeiramente são, ao passo que aqueles [os historiadores], obrigados a aderir aos fatos, acabam discordando em matéria de interpretação, o que torna as suas obras ficção" (VASCONCELOS, 2002, p. 93).

É importante observar que o ousado e controverso posicionamento de Fielding diante da história, ao ponto de caracterizá-la como "ficcional", se deve a um contexto em que o romance precisava se firmar como gênero, 
e é também por isso que o escritor inglês chega a distinguir os romances da época em "mediocres" e aqueles que seriam "história e biografia", sendo esses últimos capazes retratar a vida em sua essência e modo de ser. Novamente a designação de Fielding em denominar os "bons" romances de "história e biografia" poderia gerar uma refutação frente a sua distinção entre o papel do romancista e do historiador, pois se o segundo ao produzir romances de qualidade estaria próximo ao historiador, como poderia ser esse inferior ao próprio romancista? A resposta pode ser inferida no "aprisionamento" do historiador diante dos fatos, o que faz com que a narrativa construida por ele ao interpretá-los se enviese pelo inverídico, pois se distancia do mundo conforme ele é, enquanto isso o romancista, ainda que use o fantasioso e a imaginação, busca com profundidade captar a verdade do mundo, das relações entre os homens e a materialidade da vida.

Foi durante o século XX que o diálogo da história com a literatura ganhou novos rumos, sem que tenha deixado de lado o campo de tensão que dominou esse contato. Isso se deu principalmente devido à abertura a que a história se submeteu a partir da primeira metade desse século, surgindo, a partir de uma crise que era também das ciências sociais e humanas, uma nova maneira de construir a história e a escrita histórica. A preocupação deixa de ser a narrativa dos acontecimentos e se transfere para a análise de estruturas, situação que cede espaço, por exemplo, para que a microhistória e a teoria da literatura passem a figurar como meio de construir a história. O berço teórico dessa transformação deve ser buscado nos pensadores que estavam envolvidos na articulação da Revista Les Annales d' Histoire Économique et Sociale em 1929, na França. É a partir deles, inicialmente representados por Lucien Febrve e Marc Bloch, que surge a nomenclatura da "nouvelle histoire, concepção dentro da história responsável por pensar a construção histórica a partir de uma negação a determinadas crenças que a corrente tradicional outorgava. Segundo Hunt (1992), a explicação para essa virada no campo histórico, que passa a ser melhor vislumbrada a partir da segunda metade do século XX, deve ser encontrada não somente na escola dos "Annales", mas também na influência do marxismo, que embora não fosse mais novidade, vinha arraigado a novas correntes que pautavam o interesse dos historiadores no âmbito da história social.

Considerando as concepções restritivas da História Positivista e os discursos canônicos consolidados ao longo dos séculos, a Nova História, que surge como nomenclatura somente a partir do ano de 1978 através de uma das edições da revista Annales: économies, societés, civilisations, propõe 
uma construção da história que não mais se embase nas concepções de heroísmo e nas figuras ilustres que representam a elite, mas que reaja ao chamado "paradigma tradicional", possibilitando uma abertura à realidade mutável, analisando as estruturas, valorizando documentos, registros, arquivos (em maior número possível) e valorizando as "opiniões das pessoas comuns e com sua experiência da mudança social” (BURKE, 1992, p. 13).

Um dos elementos do discurso histórico que a Nova História (ou História Nova, as nomenclaturas são várias) se propõe a contestar relacionase ao fato de um mesmo acontecimento ser interpretado de modo diverso de acordo com marcações específicas do historiador, como sexo, raça e classe social. Logo, ao analisar a tendência unilateral adotada pela História Positivista, percebe-se a importância em postular a multiplicidade de versões acerca dos fatos e dar voz os vários sujeitos históricos. Isso explica a abertura da história no sentido de dialogar com outras áreas das ciências humanas, como a sociologia, a psicologia e a antropologia, em busca de novas maneiras de abordar o passado, o que configurou, inclusive, novos rumos para a relação história e literatura.

Essa mudança aconteceu de modo gradativo no decorrer do século $\mathrm{XX}$, pois enquanto os paradigmas marxistas e da escola dos "Annales" destituíam a hegemonia da história política para direcionar a atenção na história econômica e social, que dominou os estudos até a década de 1970, o que se pôde observar a partir daí foi uma transformação em direção a uma abordagem da história pelo viés cultural. Foi esse desvio para a cultura o responsável por uma maior preocupação por parte dos historiadores pelos aspectos linguísticos, inclusive, conforme afirma Hunt (1992, p. 6), muitos deles argumentavam "que a atenção à linguagem podia desafiar as 'teorias reflexivas do conhecimento' e afetar a prática dos 'historiadores socialistas' ao focalizar as funções 'semióticas' da linguagem". Embora os posicionamentos resistentes, o que se observou foi uma expansão da erudição histórica e um alargamento dos limites tradicionais da historiografia, o que trouxe uma proximidade ainda maior entre a história e a crítica literária, evidenciando a preocupação em relação à atuação da linguagem na abordagem do passado.

Dois historiadores tomaram a linha de frente na defesa da importância da linguagem e da crítica literária na construção da história, são eles Dominick LaCapra e o já citado Hayden White. Para eles essa aproximação, que admite a relevância da linguagem na construção da história, possibilita um enriquecimento para o trabalho do historiador e uma maior compreensão dos próprios construtos históricos. Kramer 
(1992), em seu ensaio "Literatura, crítica e imaginação histórica", em que realiza uma leitura do pensamento de LaCapra e White, afirma que os dois historiadores seguem uma linha que intelectuais que há muito reivindica uma abordagem mais diversificada da história. Nesse hall entram nomes como Nietzsche, Foucault e Derrida que, entre muitos outros, pensaram a história como uma possibilidade de desconstruir a ortodoxia epistemológica que ainda domina o pensamento europeu. É nesse sentido que Hayden White defende a aceitação da história frente a seu caráter filosófico e literário, pois, para ele, somente para os historiadores ainda ligados à definição da história conforme a rigidez cientificista do século XIX é que essa relação parece ser negativa. Porém o que White defende é a ampliação da história e da atuação do historiador, contribuindo para "ajudar a transformar a disciplina numa iniciativa mais criativa, autoconsciente e crítica" (KRAMER, 1992, p. 137). Além de considerar a importância da filosofia da história na abordagem de relatos da realidade histórica, White em suas obras se preocupa em enfatizar a proximidade entre a narrativa e a participação da imaginação no processo de criação do historiador, sem que isso signifique destituir a história de sua veracidade.

Para os dois historiadores a ampliação do território de atuação da histórica encontra na proximidade com a crítica literária uma forma de repensar suas fronteiras e questionar seu modo de abordar o passado. Para White, a análise das estruturas fictícias e filosóficas das narrativas históricas é uma maneira de buscar suas características coerentes, para La Capra, isso permite investigar o que há de incoerente na abordagem do passado, pois "as narrativas históricas e objetos de investigação das mesmas expressam tensões internas que sempre desafiam as estruturas profundas da ordem filosófica e literária [...]" (KRAMER, 1992, p. 138).

Embora as distinções nos posicionamentos de LaCapra de White, o que se nota é a preocupação desses dois estudiosos em relação às transformações pelas quais a história passou do século XIX até a atualidade e é imprescindivel, nesse contexto, considerar a abertura no sentido de dialogar com novas campos do conhecimento e aceitar a influência que a linguagem exerce sobre o trabalho do historiador. Nesse sentido, tanto para LaCapra quanto para White o que está em jogo na construção de novas formas de escrita historiográfica e de interpretação de textos e contextos do passado é o domínio de uma sensibilidade à linguagem e, por isso, um maior contato com a crítica literária e com as obras criativas da tradição literária. Não se trata, logo, de uma competição entre a literatura e a história 
sobre quem dominaria o que aconteceu no passado, mas de uma nova metodologia sobre como esse passado deve ser abordado pela história.

No trabalho realizado pelo historiador e pelo escritor é possível estabelecer, embora as idiossincrasias quando ao modo de abordagem de cada um, intersecções que se relacionam não apenas à atuação, mas consequentemente, ao objeto final desse trabalho. Ainda que seja uma aproximação não aceita por alguns historiadores, negação justificada, segundo eles, pelas características do trabalho historiográfico, é inegável a nítida proximidade entre os campos. Além disso, é preciso pensar que os dois discursos se constroem dentro de uma dinâmica que deve atender a uma forma pré-estabelecida por cada campo e, embora haja uma crença de que por lidar com aspectos da imaginação o autor da literatura tenha uma pretensa liberdade na escrita e nas escolhas a serem realizadas, em algum nível isso também diz respeito ao trabalho feito pelo historiador. Isso porque o passado, objeto primordial do seu trabalho, não se mostra diante dele a partir de sua integralidade, mas como rastros, destroços, sinais, restos que precisam ser lidos, analisados e interpretados para que tenham sentido no presente. Assim, é no seu trabalho de composição dos fatos que ele dá coerência àquilo que se apresenta disperso diante dele e, para tal empreitada, ele também precisa lidar com a escolha do que é ou não importante na reconstrução discursiva do passado, elegendo acontecimentos que, na malha do texto histórico, precisam ser apresentados de modo a possuir sentido e coerência, deixando de lado fatos que, segundo sua ótica, pouco contribuíram para que o presente se constituísse como tal. Enquanto na construção da narrativa literária o escritor, ainda que habite um campo em que a liberdade de produção/criação seja mais amplo e que oferece um maior espaço para a manifestação da imaginação, também necessita ser guiado por alguns parâmetros da própria composição literária, como, por exemplo, a verossimilhança. Assim, mesmo que a narrativa literária não sofra as imposições de elementos externos a ela, como acontece com a produção historiográfica, ela deve seguir uma linha de construção capaz de estabelecer ligações lógicas e causais para que convençam o leitor da veracidade interna dos fatos contados.

Para Hayden White, a incompletude e o caráter provisório na caracterização dos acontecimentos devem sempre ser frisados diante do leitor pelos bons profissionais da história, pois ainda há muitos historiadores tentam perpetuar o status que a narrativa história possuía outrora, ou seja, "um modelo de estruturas e processos há muito decorridos 
e, portanto, não-sujeitos a controles experimentais e observacionais", enquanto elas notadamente são, segundo o historiador estadunidense, "ficções verbais cujos conteúdos são tanto inventados quanto descobertos e cujas formas têm mais em comum com os seus equivalentes na literatura do que com os seus correspondentes nas ciências" (WHITE, 1994, p. 98, grifos do autor).

Em um sentido oposto, Northrop Frye acusa que há uma distância existente entre a história e o mito, embora em alguns casos o trabalho do historiador possa beirar o mítico quanto ao atingir determinada abrangência e universalidade sua estrutura se assemelha à poética. Porém, ainda que para Frye (1978) exista essa possibilidade, o que marca o trabalho do historiador não é uma busca pela adequação a uma determinada forma ou padrão, mas são os próprios fatos colhidos que vão direcionar a abordagem e estruturação que será feita diante deles, desvencilhando as ações do historiador das do poeta, por exemplo.

Costa Lima, em A aguarrás do tempo (1989), também se preocupa em analisar a relação do mito com as narrativas histórica e ficcional. Para o autor, a origem do mito está na Grécia e foi a partir dele que derivaram a história e a tragédia. Para o estudioso, na busca por este conhecimento mitológico enquanto conceito, concentra-se a possibilidade de se distinguir, com maior precisão, as diferenças e semelhanças entre narrativa histórica e ficcional.

Segundo o autor, ambas possuem relações variadas com o mundo e com a verdade. A história, que pressupõe sempre uma narrativa, reúne frações, dados, acontecimentos, ordenando a matéria do passado num todo, na perspectiva interpretativa do historiador, inserido em um contexto. A ficção, por sua vez, pode ser classificada como a "representação desestabilizante das representações” (LIMA, 1989, p. 102), uma criação a partir de um determinado objeto, fato ou uma espécie de verdade primeira, que se distancia, possuindo uma orientação singular que nem sempre contém correspondência com a verdade referida. Neste campo de diferenciação de objetivos e propostas, Costa Lima aponta características acerca da linguagem ficcional e histórica, pois, segundo ele, linguagem, partindo do verossímil, seria a grande marca distintiva entre os tipos de narrativa em questão. Para a ficção, a linguagem apresentaria maiores possibilidades, lidando com uma aparência de verdade, uma quase verdade, e uma gama de mundos imaginários, enquanto a cientificidade entraria como pressuposto da escrita histórica, que lida com documentos, possuindo um caráter de construção de verdade. 
Porém, seguindo a perspectiva de Frye, ainda que o fazer historiográfico não se guie por padrões formais pré-estabelecidos, ao entrar em contato com os fatos do passado é necessário que o historiador seja capaz de explicá-los de modo a criar um enredo, uma crônica que traduza seu contato com os registros históricos e que possa ser compreendido pelo leitor, o que já o aproxima da produção da caráter ficcional. Além disso, é relevante frisar o quão desordenados, incompletos e distantes de uma narrativa com sentido são os materiais com os quais o historiador precisar trabalhar e que, por isso, é a sua apropriação e sua capacidade de produzir um enredo coerente, dotado de início, meio e fim, que constituirá a história a partir do seu aspecto verossímil. Porém, para que isso seja possivel, será inevitável o uso do elemento imaginativo que associado ao que se apresenta enquanto fato documental preencherá as lacunas deixadas pela ausência da fragmentação dos dados históricos.

O que se constata enfim é que ambas narrativas possuem um caráter ficcional, o que na história surge a partir do momento em que a composição dos fatos também precisa possuir verossimilhança e, diante de um passado que se apresenta como escombros para o historiador, são suas escolhas, sua interpretação e suas interferências na organização dos acontecimentos que garantirá a leitura desse passado enquanto algo dotado de lógica causal. Essa ficcionalização da história, ao contrário do que pensam muitos historiadores avessos a aceitar tal aspecto da escrita histórica, não enfraquece ou destitui a validade do que é escrito, mas atualiza a história dentro de novas possibilidades discursivas. Sobre o posicionamento desses historiadores, Hayden White (1994) afirma que a dicotomia real versus imaginário que aparentemente domina a relação entre história e literatura deve ser desconstruída, pois a forma de dar sentido ao mundo se constitui de modo similar para o historiador e o romancista: assim como a história ganha sentido dentro do processo de evolução do mundo real, trazendo à luz o que se apresenta como distante e obscuro, o romancista ou poeta tenta, de modo análogo, dar forma e tornar familiar o que se afigura como problemático.

Sobre essa dicotomia é interessante observar a análise feita por Auerbach no ensaio "A cicatriz de Ulisses" que abre o livro Mimesis. Nesse texto o autor constrói uma comparação entre a Odisseia e a Bíblia, especificamente entre o trecho em que Ulisses retorna a Ítaca e sua cicatriz é reconhecida por Euricléia, sua antiga ama, no momento em que lava seus pés, e o trecho do livro Gênesis, do Antigo Testamento, quando Deus ordena que Abraão sacrifique seu filho Isaac. Ao analisar o modo como é 
construída a representação em cada uma das narrativas, Auerbach observa o distanciamento das escolhas discursivas feitas em cada um dos textos épicos. Em Homero há uma forte preocupação com a construção da cena de modo a não deixar lacunas, pormenorizando os acontecimentos, pois se constata que o objetivo estilístico do autor é "retratar os fenômenos acabadamente, palpáveis e visíveis em todas as suas partes, claramente definidos em suas relações espaciais e temporais" (AUERBACH, 2001, p. 4). Enquanto na Bíblia, especificamente no capítulo 22 do livro de Gênesis, a narração redigida pelo chamado Eloísta é composta de modo lacunar, incompleto, "só é acabado formalmente aquilo que nas manifestações interessa à meta da ação; o restante fica na escuridão" (AUERBACH, 2001, p. 9).

Ao analisar o contexto das duas narrativas, percebe-se que a Bíblia estava muito mais pretensa à verdade que os livros de Homero. Tanto o narrador Eloísta quanto os leitores do relato sobre o sacrifício do filho de Abraão tendiam a crer, pelo objetivo de fundo religioso, na verdade histórica inscrita na narrativa, mesmo ela sendo tão fragmentária. Diferente de Homero, que aceitava objeções sobre a verdade de sua narrativa, o narrador bíblico não abre possibilidade quanto a isso, pois o relato bíblico vê somente a sua versão como a única possível e aceitável. Assim, Homero estaria tão próximo do mítico e do lendário quanto a Bíblia do histórico, e isso se daria, inclusive, pela sua organização desordenada e menos uniforme desse último. Porém, em ambos os casos é possivel entrever a realidade histórica de uma época, condição rejeitada pela história ao afirmar que a subjetividade da narrativa literária impossibilita o acesso ao real.

Na comparação feita por Auerbach, a Bíblia está mais próxima da história também porque seu modo de registrar os acontecimentos é uma tentativa de apreendê-los de maneira mais semelhante conforme os presenciamos: desordenados, muitas vezes incoerentes e confusos. Porém, no caso do registro histórico, é a construção da narrativa que consegue ordenar os acontecimentos, que nos parecem tão desarticulados, de maneira a terem lógica. E é nesse sentido que Auerbach (2001, p. 17) afirma que "Escrever história é tão difícil que a maioria dos historiadores vê-se obrigada a fazer concessões à técnica do lendário", confirmando parecer inevitável que a história se aproxime da literatura, inclusive, pelo modo como as duas dão sentido ao que registram.

Ao analisar a relação entre os dois campos, Costa Lima afirma que há uma "tendência à confusão entre as formas discursivas da história e da ficção” (LIMA, 1989, p. 101), e alega que a relação confusa que se faz entre 
os dois formatos textuais é remota e deve-se, sobretudo, ao estatuto conferido a esses textos e ao arranjo narrativo de cada um. Para o autor, o parentesco entre a escrita histórica e a ficcional remonta a dois tipos de relato: de um lado, o que objetivava demonstrar um mundo estável, baseado em leis e em mitos; de outro, aquele que procurava narrar o peculiar, o instável, o excessivo. E ao longo da história da humanidade foi a essas duas formas a que se recorreu para narrar. Porém, embora a história e a literatura se constituam por meio da narrativa, há diferenciações que apontam o modo como cada uma delas se relaciona com o mundo: enquanto o historiador tenta designá-lo ao constituir os destroços deixados pelo passado no sentido de moldar uma ordem, o escritor se preocupa em desconstruir, através da representação, as representações já existentes no nele, o que possibilita novas orientações sobre o mundo.

Uma teórica importante que também se debruça sobre a relação entre os dois campos é Linda Hutcheon. Segundo ela, até o século XIX, antes do aparecimento da linhagem cientificista, a história era considerada como pertencente a uma mesma ramificação do saber da literatura, visto terem como objetivo a interpretação das experiências, visando a elevação humana. Porém a obstinada vontade de envolver a história em um invólucro de ciência trouxe uma diluição desta aproximação e o que marca os discursos teóricos sobre o tema na atualidade é uma contestação em relação a esse afastamento, tentando aproximar novamente os dois discursos por meio do que eles possuem em comum, evitando centrar nas suas distinções (HUTCHEON, 1991). A verossimilhança seria um dos elementos de aproximação, pois é dela que tanto a literatura quanto a história retira a força de seus discursos, ambos pautados nos construtos linguísticos, nas intertextualidades e em convenções narrativas "nada transparentes em termos de linguagem ou de estrutura" (HUTCHEON, 1991, p. 141). Porém, a crítica e teórica canadense alerta para o fato de história e ficção serem construtos históricos que sofreram e sofrem alterações com o passar do tempo, por isso a relação entre os dois campos se plaina em um terreno de instabilidade.

O que se nota enfim desta relação tão antiga entre a história e a literatura é que embora as duas tenham estabelecido contatos contínuos e sofrido aproximações por motivos vários ao longo dos tempos, a relação entre esses dois campos ainda se encontra sob o domínio das diferenças, principalmente acentuadas pelos discursos historiográficos que ainda hoje tentam debitar da literatura qualquer valor de verdade, depositado somente no que produz a história. Porém, como pontua Barthes em seu ensaio "O 
discurso da história", o discurso histórico que ao longo dos tempos foi envolvido pelo invólucro de "racional" e pautado no "real" recai enquanto um "discurso" que necessita ser "construído" em bases semelhantes às da ficção: é produzido por alguém prenhe de ideologia e que necessita da linguagem para atribuir sentido ao que é narrado. Para Barthes, é através da linguagem, ou do imaginário, que o historiador se projeta no texto enquanto enunciador e isso contribui para a desconfiança gerada acerca da pretensa objetividade histórica. Além disso, a crença numa suposta "realidade" do discurso histórico se baseia na ilusão de que nele é possivel apenas um sistema semântico em que existem somente referente e significado. Porém, esse "efeito de real" mascara o que realmente faz a história: ela não acompanha o real, mas somente produz mais significações sobre ele, "não faz mais que significá-lo" (BARTHES, 2004, p. 178). As conclusões a que chega Barthes destituem a história da sua possibilidade de figurar enquanto ciência pura, pois como afirmou Nietzsche, "Não existe fato em si. É sempre preciso começar por introduzir um sentido para que haja um fato", e é essa manipulação inevitável que torna improvável as fortes relações de proximidade entre história e ficção.

A relação entre ficção e história ganhou novo fôlego a partir de produções literárias que passaram a questionar de maneira mais veemente a reconstrução do passado produzida pela história. Embora as bases dessas produções estejam no romance histórico, em que não se via uma tentativa de subversão e crítica sobre como o passado era visto pela história, o que caracteriza alguns romances produzidos a partir da segunda metade do século XX é o questionamento da relação entre história e realidade, história e linguagem e sobre como o passado, composto por escombros dispersos e incompletos, é lido pela ótica da história. Esses romances, inseridos no contexto histórico, cultural e social em que foram/são produzidos respondem a questionamentos de um momento em que a relação entre os dois campos já não pode mais ser lida pelos mesmos vieses de outrora, uma vez que as mudanças ocorridas instauraram novas problematizações de ordens estruturais e temáticas que suscitam outras respostas e reflexões.

\section{REFERÊNCIAS}

AUERBACH, Erich. Mimesis: representação da realidade na literatura ocidental. Tradução George Bernard Sperber. São Paulo: Perspectiva, 2001. 
BARTHES, Roland. O Rumor da língua. Tradução André Stahel M. da Silva. 2a ed. São Paulo, 2004.

COSTA LIMA, Luiz. A aguarrás do tempo: estudos sobre a narrativa. Rio de Janeiro: Rocco, 1989.

FRYE, Northrop. Anatomia da crítica. Trad. Perícles Eugênio da Silva Ramos. São Paulo, Cultirx, 1978.

HUNT, Lynn. A nova história cultural. Tradução de Jefferson Luiz Camargo. São Paulo: Martins Fontes, 1992. p. 1-29.

HUTCHEON, Linda. Poética do pós-modernismo: história, teoria, ficção. Tradução de Ricardo Cruz. Rio de Janeiro: Imago, 1991.

KRAMER, Lloyd S. Literatura, crítica e imaginação histórica: O desafio literário de Hayden White e Dominick LaCapra. In: HUNT, Lynn. A nova história cultural. Tradução de Jefferson Luiz Camargo. São Paulo: Martins Fontes, 1992.

VASCONCELOS, Sandra Guardini. Dez lições sobre o romance inglês do século XVIII. São Paulo: Boitempo, 2002.

Recebido em: 15/06/2016

Aceito em: 27/07/2016 